\title{
Mycobacterium avium Chester Request for an Opinion
}

\author{
ERWIN F. LESSEL \\ American Type Culture Collection, Rockville, Maryland 20852
}

\begin{abstract}
The first scientific name applied to the agent of avian tuberculosis was Bacillus tuberculosis gallinarum Sternberg. This name was validly published, and it is legitimate. The specific epithet conveys a single idea even though it consists of two words; these should be hyphenated and regarded as a single specific epithet. However, the name that has been used for this organism for decades is Mycobacterium avium, a name ordinarily attributed to Chester. Although there is some question concerning the validity of publication of the name Mycobacterium avium Chester and even though the specific epithet is illegitimate, the Judicial Commission of the International Committee on Systematic Bacteriology is asked to conserve this name in the interest of stability in nomenclature.
\end{abstract}

Maffucci (4) described the agent of avian tuberculosis but did not apply a scientific name to the organism. He referred to it as "der Bacillus der Hühnertuberculose" and as "der Bacillus der Geflügeltuberculose." The first to give a scientific name to the organism described by Maffucci was Sternberg (5), who called it Bacillus tuberculosis gallinarum. This name was validly published, and it is legitimate. (N.B. The specific epithet, although consisting of two words, conveys a single idea, tuberculosis of chickens, and it is therefore to be hyphenated and regarded as a single specific epithet.) Mycobacterium tuberculosis avium was a name applied to Maffucci's organism by Lehmann and Neumann (3), who incorrectly cited "Bacillus tuberculosis avium Maffucci" as a synonym. It appears that Kruse (2) was the first to use the name Bacillus tuberculosis avium. In any event, the specific epithet "tuberculosisavium" is illegitimate because it is antedated by "tuberculosis-gallinarum." In 1901 Chester (1) used the name "Mycobacterium avium (Kruse) Lehmann-Neumann" to refer to Maffucci's organism. The citation of Kruse's name in parentheses as the author of the basionym is incorrect: Kruse used "tuberculosis avium," not "avium" alone. Furthermore, Lehmann and Neumann also used "tuberculosis avium," not "avium" by itself.

It is impossible to determine, at this date, how Chester came to use $M$. avium Lehmann and Neumann instead of $M$. tuberculosis avium Lehmann and Neumann. There are at least four possibilities: (i) the deletion of "tuberculosis" was a typographical error; (ii) Chester thought "tuberculosis avium" to be incorrect and "corrected" it to "avium"; (iii) Chester interpreted $M$. tuberculosis avium as $M$. tuberculosis subspecies avium and elevated the subspecies to species rank; and (iv) Chester preferred "avium" to "tuberculosis avium" because of the brevity of the former.

Although Chester's intention cannot now be determined, the name Mycobacterium avium has come into common usage for the agent of avian tuberculosis, and Chester is always cited as the author of this name. Clearly there is some question as to whether Mycobacterium avium was validly published by Chester; it is also obvious that the specific epithet "avium" is illegitimate because of the priority of "tuberculosis-gallinarum." However, because Mycobacterium avium has for decades been used almost universally as the name of the organism which causes avian tuberculosis, it is hereby requested that, in the interest of stability in nomenclature, the Judicial Commission of the International Committee on Systematic Bacteriology make an exception to the rules and issue an Opinion conserving the name Mycobacterium avium, with Chester (1) as the author of this name. 


\section{LITERATURE CITED}

1. Chester, F. D. 1901. A manual of determinative bacteriology, p. 1-401. The Macmillan Co., New York.

2. Kruse, W. 1896. Systematik der Streptothricheen und Bakterien, p. 48-66, 67-96, 185-526. In C. Flügge (ed.), Die Mikroorganismen, vol. 2. F. C. W. Vogel, Leipzig, Germany.
3. Lehman, K. B., and R. Neumann 1896. Atlas und Grundriss der Bakteriologie und Lehrbuch der speciellen bakteriologischen Diagnostik, vol. 2. J. F. Lehmann, Munich, Germany.

4. Maffucci, A. 1892. Die Hühnertuberculose. Z. Hyg. Infektionskr. 11:445-486.

5. Sternberg, G. M. 1892. Manual of bacteriology. W. Wood and Co., New York. 